\title{
ESTIMASI NILAI VaR PORTOFOLIO MENGGUNAKAN FUNGSI ARCHIMEDEAN COPULA
}

\author{
Aulia Atika Prawibta Suharto $^{1 \S}$, Komang Dharmawan ${ }^{2 \S}$, I Wayan Sumarjaya ${ }^{3}$ \\ ${ }^{1}$ Jurusan Matematika, FMIPA - UniversitasUdayana [Email: auliaatika08@ gmail.com] \\ ${ }^{2}$ Jurusan Matematika, FMIPA - UniversitasUdayana [Email: k.dharmawan@unud.ac.id] \\ ${ }^{3}$ Jurusan Matematika, FMIPA - UniversitasUdayana [Email: sumarjaya@unud.ac.id] \\ ${ }^{\S}$ Corresponding Author
}

\begin{abstract}
Value at Risk explains the magnitude of the worst losses occurred in financial products investments with a certain level of confidence and time interval. The purpose of this study is to estimate the VaR of portfolio using Archimedean Copula family. The methods for calculating the VaR are as follows: (1) calculating the stock return; (2) calculating descriptive statistics of return; (3) checking for the nature of autocorrelation and heteroscedasticity effects on stock return data; (4) checking for the presence of extreme value by using Pareto tail; (5) estimating the parameters of Achimedean Copula family; (6) conducting simulations of Archimedean Copula; (7) estimating the value of the stock portfolio VaR. This study uses the closing price of TLKM and GGRM. At 90\% the VaR obtained using Clayton, Gumbel, Frank copulas are 0.9562\%, 1.0189\%, 0.9827\% respectively. At 95\% the VaR obtained using Clayton, Gumbel, Frank copulas are 1.2930\%, 1.2522\%, $1.3152 \%$ respectively. At $99 \%$ the VaR obtained using Clayton, Gumbel, Frank copulas are $2.0327 \%, 1.9164 \%$, is $1.8678 \%$ respectively. In conclusion estimation of VaR using Clayton copula yields the highest VaR.
\end{abstract}

Keywords: Portfolio, Value at Risk, Copula, Arhimedean Copula.

\section{PENDAHULUAN}

Investasi adalah salah satu alternatif cara yang dapat digunakan untuk meningkatkan aset pada masa mendatang. Banyak orang melakukan investasi dengan tujuan untuk mendapatkan keuntungan pada masa mendatang. Untuk melakukan investasi seorang investor harus dapat memperkirakan keuntungan dan kerugian yang mungkin akan diperoleh. Investasi yang sering dilakukan di Indonesia adalah investasi emas, properti dan saham. Emas dan properti merupakan investasi real aset sedangkan saham merupakan investasi aset finansial.

Investasi dalam saham adalah bentuk investasi yang paling umum di pasar modal. Saham dapat didefinisikan sebagai tanda atau pemilikan seseorang atau badan dalam suatu perusahaan atau perseroan terbatas (Jogianto, 2003). Dengan berinvestasi pada berbagai saham perusahaan, investor ingin mendapatkan return yang setinggi-tingginya. Namun investasi dalam saham juga mengandung unsur risiko apabila harga saham mempunyai fluktuasi tinggi yang sangat dipengaruhi oleh kondisi perusahaan (faktor teknik) dan kondisi fundamental baik perencanaan domestik maupun regional dan internasional. Jadi dalam berinvestasi saham terdapat dua unsur yang saling memengaruhi yaitu tingkat pengembalian (return) dan risiko (risk) yang harus ditanggung investor. Jika investor menginginkan tingkat pengembalian yang tinggi maka investor harus berani menanggung risiko yang tinggi juga. Oleh karena mengukur dan mengelola risiko pada saham-saham yang dipilih merupakan hal yang sangat penting dalam berinvestasi.

Secara umum, mengelola risiko sering kali mengacu pada struktur kebergantungan masingmasing peubah acak tingkat pengembalian (return) harus memenuhi asumsi-asumsi seperti berdistribusi normal, distribusi tingkat 
pengembalian (return) tidak memiliki ekor gemuk (heavy tail), serta variabel bergantung secara linear. Dari asumsi-asumsi yang harus dipenuhi tersebut salah satu fungsi yang dapat diterapkan adalah fungsi copula.

Copula adalah suatu fungsi yang menggabungkan beberapa distribusi marjinal menjadi distribusi gabungan. Copula berasal dari bahasa Latin yaitu copula yang berarti ikatan atau mengikat. Konsep copula pertama kali dipopulerkan oleh seorang matematikawan bernama Abe Sklar pada tahun 1959 yang teoremanya dikenal dengan nama Teorema Sklar. Fungsi copula memiliki konsep sebagai alat untuk mempelajari kebergantungan tidak linear antara kejadian dalam kasus multivariat. Copula memiliki beberapa keunggulan antara lain tidak memerlukan asumsi distribusi normal dan dapat menunjukkan adanya pola sebaran data pada ekor distribusi masing-masing variabel. Keluarga copula yang umum dikenal ialah keluarga Eliptik copula yang terdiri dari Gaussian copula dan t-Student copula, sedangkan keluarga Archimedean copula terdiri dari Gumbel copula, Clayton copula, dan Frank copula (Nelsen, 2006).

Pengukuran risiko investasi yang popular digunakan adalah Value at Risk (VaR). Value at Risk menjelaskan besarnya kerugian terburuk yang terjadi pada investasi dalam produk finansial dengan tingkat kepercayaan tertentu dan dalam interval waktu tertentu. Beberapa metode telah dikembangkan untuk menaksir Value at Risk, seperti simulasi data historis, simulasi Monte Carlo, dan Exponentially Weighted Moving Average (Dharmawan, 2014).

Dalam penelitian ini digunakan dua saham yaitu PT. Telekomunikasi Indonesia Tbk (TLKM), dan PT. Gudang Garam Tbk (GGRM). Tujuan penelitian ini adalah untuk mengestimasi nilai Value at Risk menggunakan keluarga Archimedean copula.

Return saham adalah keuntungan yang dinikmati investor atas investasi saham yang dilakukannya. Jogiyanto (2003) menyatakan return saham dapat dibedakan menjadi dua yaitu realisasi return dan ekspektasi return. Realisasi Return merupakan return yang telah terjadi sedangkan return ekspektasi merupakan return yang diharapkan akan diperoleh investor dimasa yang akan datang. Menurut Sunaryo (2007:31) perhitungan return dapat dirumuskan sebagai berikut :

$$
r_{t, i}=\frac{s_{t, i}-s_{t-1, i}}{s_{t-1, i}} .
$$

Persamaan (1) digunakan untuk menghitung tingkat pengembalian (return) diskret atau realisasi return, sedangkan untuk menghitung tingkat pengembalian (return) kontinu dapat dirumuskan sebagai beikut:

$$
r_{t, i}=\ln \left(\frac{s_{t, i}}{s_{t-1, i}}\right)
$$

Persamaan (2) disebut juga logarithmic return, dengan $r_{t, i}$ menyatakan tingkat pengembalian (return) saham pada period ke- $t$ untuk saham $i, S_{t, i}$ menyatakan harga saham pada periode ke-t, untuk saham $i$ dan $S_{t-1, i}$ menyatakan harga saham pada periode ke $t-1$ untuk saham $i$.

Copula adalah suatu fungsi yang menggabungkan beberapa distribusi marjinal menjadi distribusi gabungan. Copula berasal dari bahasa Latin yaitu copula yang berarti ikatan atau mengikat. Konsep copula pertama kali dipopulerkan oleh seorang matematikawan bernama Abe Sklar pada tahun 1959 yang teoremanya dikenal dengan nama Teorema Sklar. Fungsi copula memiliki konsep sebagai alat untuk mempelajari kebergantungan tidak linear antara kejadian dalam kasus multivariat. Copula memiliki beberapa keunggulan antara lain tidak memerlukan asumsi distribusi normal dan dapat menunjukkan adanya pola sebaran data pada ekor distribusi masing-masing variabel.

Salah satu keluarga copula yang popular digunakan adalah keluarga Archimedean copula. Anggota keluarga Archimedean copula adalah Clayton copula, Gumbel copula, dan Frank copula.

Value at Risk (VaR) merupakan suatu ukuran risiko yang menghitung besarnya kerugian maksimum yang mungkin dialami 
dalam suatu periode tertentu. VaR dapat didefinisikan sebagai berikut:

$$
\operatorname{VaR}(\alpha)=F_{L}^{-1}(\alpha)
$$

dengan $F_{L}^{-1}(\alpha)$ adalah invers dari suatu distribusi dari $\alpha$.

\section{METODE PENELITIAN}

Data yang digunakan dalam penelitian ini meliputi dua saham yaitu PT. Telekomunikasi Indonesia Tbk (TLKM), dan PT. Gudang Garam Tbk (GGRM). Data yang digunakan adalah data sekunder harga penutupan (closing price) saham harian periode 1 Januari 2014 sampai 6 November 2016. Pemilihan harga penutup (closing price) saham disebabkan penggunaannya sebagai indikator harga pembukaan hari berikutnya. Data penutup saham tersebut dapat diakses pada situs www.finance.yahoo.com.

Untuk menganalisis data portofolio akan digunakan program MATLAB. Langkahlangkah yang digunakan adalah (1) menghitung return saham TLKM dan saham GGRM; (2) mencari nilai tengah, simpangan baku, skewness, dan kurtosis, dari return saham TLKM dan saham GGRM; (3) memeriksa ada atau tidaknya autokorelasi menggunakan ACF dan efek heteroscedasticity menggunakan ARCH pada data return saham TLKM dan saham GGRM; (4) memeriksa adanya nilai ekstrem dengan Pareto tail yang merupakan bagian dari pendekatan GPD; (5) mengestimasi parameter $\theta$ Archimedean Copula, dengan metode MLE; (6) melakukan simulasi Archimedean Copula; (7) mengestimasi nilai Value at Risk (VaR) saham portofolio menggunakan Archimedean Copula; (8) setelah mengestimasi nilai VaR saham potofolio menggunakan Archimedean Copula selanjutnya melakukan interpretasi hasil.

\section{HASIL DAN PEMBAHASAAN}

\subsection{Menghitung Nilai Return}

Nilai return saham diperoleh dari mengelola data closing price dari saham PT. Telekomunikasi Indonesia Tbk (TLKM), dan
PT. Gudang Garam Tbk (GGRM). Plot return dari kedua saham dapat dilihat pada Gambar 1 .
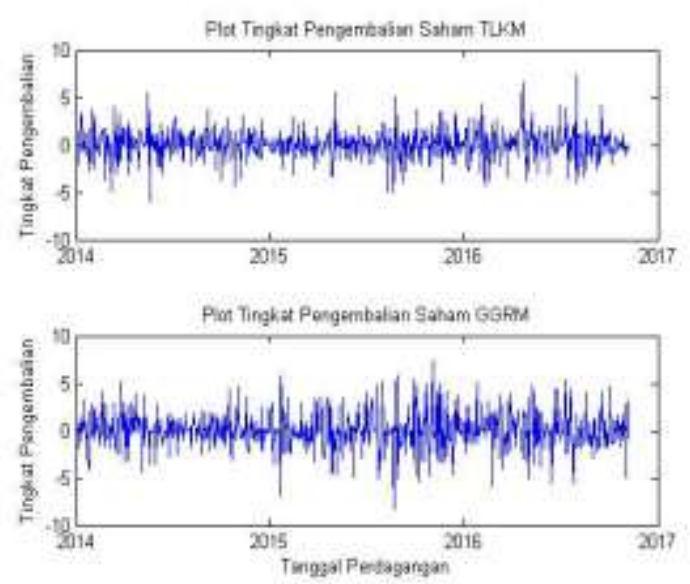

Gambar 1. Plot Return Saham TLKM dan GGRM

\subsection{Nilai Statistik Deskriptif}

Nilai statistik deskriptif data saham PT. Telekomunikasi Indonesia Tbk (TLKM), dan PT. Gudang Garam Tbk (GGRM) dapat dilihat pada Table 1.

Tabel 1. Nilai Statistik Deskriptif

\begin{tabular}{|c|c|c|}
\hline \multirow{2}{*}{ Statistik } & \multicolumn{2}{|c|}{ Saham } \\
\cline { 2 - 3 } & TLKM & GGRM \\
\hline Mean & 0,0898 & 0,0639 \\
\hline $\begin{array}{c}\text { Standard } \\
\text { Devistion }\end{array}$ & 1,5313 & 1,9936 \\
\hline Skewness & 0,0141 & $-0,0153$ \\
\hline Kurtosis & 5,1360 & 4,0838 \\
\hline
\end{tabular}

Dapat dilihat pada Tabel 1 menunjukkan bahwa return saham PT. Telekomunikasi Indonesia Tbk (TLKM), dan PT. Gudang Garam Tbk (GGRM) tidak berdistribusi normal karena nilai skewness pada return saham PT. Telekomunikasi Indonesia Tbk (TLKM) sebesar 0,0141 yang artinya skewness bernilai positif. Hal ini menunjukkan plot sebaran return pada saham Telekomunikasi Indonesia memiliki kemiringan ekor yang lebih memanjang ke kanan dibandingkan pada plot sebaran data distribusi normal. Sedangkan nilai skewness pada return saham PT. Gudang Garam tbk (GGRM) sebesar-0,0153 yang artinya skewness bernilai negatif . Hal ini menunjukkan 
plot sebaran return pada saham PT. Gudang Garam tbk (GGRM) memiliki ekor kemiringan ekor yang lebih memanjang ke kiri dibandingkan pada plot sebaran data berdistribusi normal. Selain itu, nilai kurtosis dari return saham Telekomunikasi Indonesia sebesar 5,1360 dan nilai kurtosis dari return saham PT. Gudang Garam Tbk (GGRM) sebesar 4,0838. Dengan kata lain, plot sebaran return saham PT. Telekomunikasi Indonesia Tbk (TLKM) memiliki kurtosis yang lebih tinggi dibandingkan dengan data pada distribusi normal, yang artinya kurtosis pada kedua saham memiliki keruncingan leptokortik.

\subsection{Autokorelasi dan Heteroscedasticity}

Untuk mengetahui apakah saham PT. Telekomunikasi Indonesia Tbk (TLKM), dan PT. Gudang Garam Tbk (GGRM) memiliki autokorelasi yang signifikan dapat dilihat menggunakan plot ACF return pada Gambar 2.
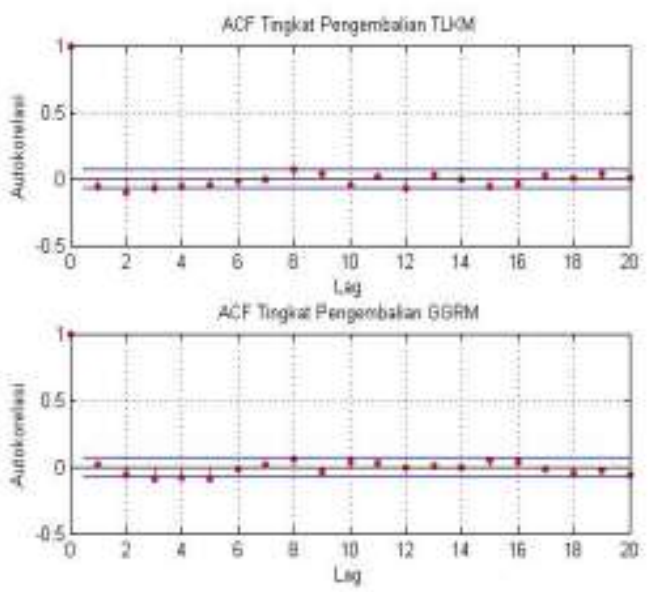

Gambar 2. Plot ACF return Telkom dan Gudang Garam

Pada Gambar 2 terlihat sebagian besar lag dari return saham PT. Telekomunikasi Indonesia Tbk (TLKM) tidak keluar dari garis bartlett hal ini menunjukkan saham PT. Telekomunikasi Indonesia Tbk (TLKM) tidak berautokorelasi. Sedangkan pada saham PT. Gudang Garam Tbk (GGRM) sebagian besar lag return saham keluar dari garis bartlett menunjukkan bahwa return saham PT. Gudang Garam Tbk (GGRM) berautokorelasi. Untuk memperjelas ada tidaknya autokorelasi, akan dilakukan uji statistika Ljung-Box yang dapat dilihat pada Tabel 2 sebagai berikut:

Adapun hipotesis uji Ljung-Box return saham PT. Telekomunikasi Indonesia Tbk (TLKM), dan PT. Gudang Garam Tbk (GGRM) sebagai berikut:

$H_{0}$ : return saham tidak berautokorelasi.

$H_{1}$ : return saham berautokorelasi.

Tabel 2. Uji Ljung-Box

\begin{tabular}{|l|l|l|l|}
\hline \multirow{2}{*}{ Saham } & \multicolumn{3}{|c|}{ Ljung-Box } \\
\cline { 2 - 4 } & P-Value & Qstat & $\begin{array}{l}\text { Critical } \\
\text { Value }\end{array}$ \\
\hline TLKM & 0,1701 & 25,8724 & 31,4104 \\
\hline GGRM & 0,0000 & 56,8444 & 31,4104 \\
\hline
\end{tabular}

Pada Tabel 2 dapat dilihat nilai P-Value saham Telekomunikasi Indonesia lebih besar dari $\alpha=0,05$ dan nilai Qstat lebih kecil dari pada nilai $\mathrm{CV}$. Hal ini menunjukkan bahwa terima $H_{0}$ atau tolak $H_{1}$, yang artinya return saham Telekomunikasi Indonesia tidak berautokorelasi. Sedangkan dapat dilihat nilai PValue saham Gudang Garam lebih kecil dari $\alpha=0,05$ dan nilai Qstat lebih besar dari pada nilai CV. Hal ini menunjukkan bahwa terima $H_{1}$ atau tolak $H_{0}$, yang artinya return saham Gudang Garam berautokorelasi.

Selanjutnya akan diperiksa ada tidaknya efek heteroskedastisitas pada return saham PT. Telekomunikasi Indonesia Tbk (TLKM), dan PT. Gudang Garam Tbk (GGRM). Efek heteroskedasticity dapat dilihat menggunakan plot ACF kuadrat return pada Gambar 3.
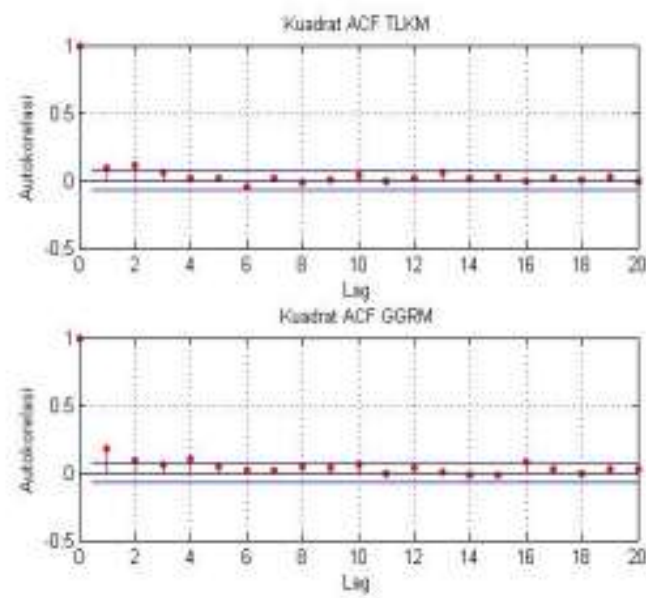

Gambar 3. Plot ACF Kuadrat Return TLKM dan GGRM. 
Gambar 3 menunjukkan sebagian besar lag pada ACF kuadrat return dari saham PT. Telekomunikasi Indonesia Tbk (TLKM), dan PT. Gudang Garam Tbk (GGRM) keluar dari garis bartlett. Hal ini mengidentifikasi adanya sifat heteroskedastisitas pada data. Untuk memperjelas ada efek heteroskedastisitas akan dilakukan uji ARCH LM yang akan dilihat pada Tabel 3 sebagai berikut:

$H_{0}$ : Homokedastisitas, tidak ada efek ARCH pada return saham

$H_{1}$ : Heteroskedastisitas, ada efek ARCH pada return saham

Tabel 3. Uji ARCH LM

\begin{tabular}{|l|l|l|l|}
\hline \multirow{2}{*}{ Saham } & \multicolumn{3}{|c|}{ ARCH LM } \\
\cline { 2 - 4 } & P-Value & Qstat & CV \\
\hline BNI & 0,0099 & 16,6537 & 3,8415 \\
\hline GGRM & 0,0000013172 & 23,3980 & 3,8415 \\
\hline
\end{tabular}

Pada Tabel 3 dapat dilihat nilai P-Value lebih kecil dari $\alpha=0,05$ dan nilai Qstat lebih besar daripada nilai CV. Hal ini menunjukkanbahwa tolak $H_{0}$ atau terima $H_{1}$, yang artinya return saham Telekomunikasi Indonesia dan saham Gudang Garam bersifat heteroskedastisitas dengan kata lain terdapat efek ARCH pada return masing-masing saham.

\subsection{Pareto Tail}

Pada data finansial sering kali terjadi kasus ekor gemuk (heavy tail) yang mengindikasi adanya nilai ekstrem. Untuk melihat adanya indikasi nilai ekstrim tersebut dapat digunakan plot Pareto tail seperti Gambar 4

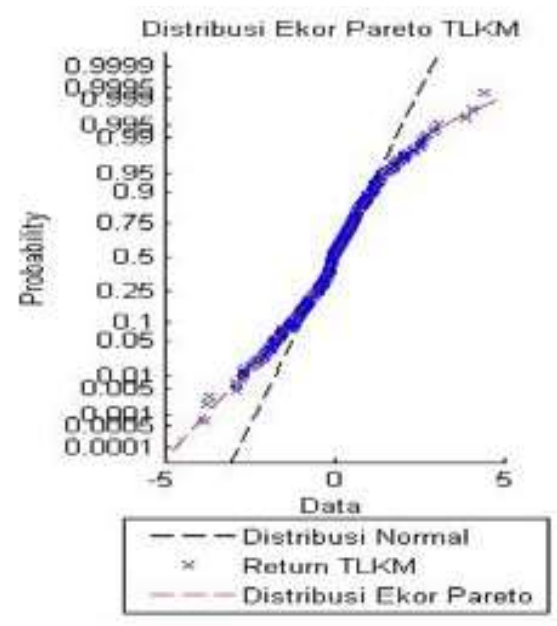

(a)

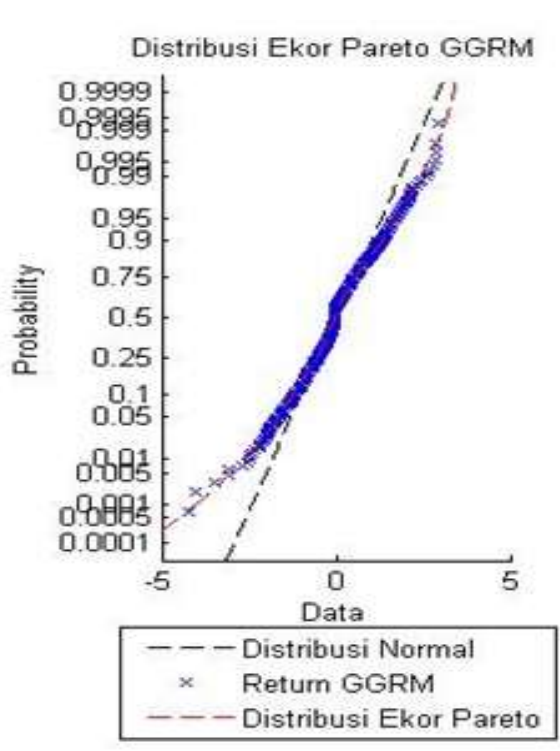

(b)

\section{. Gambar 4. Plot Pareto Tail}

Pada Gambar 4 dapat dilihat adanya indikasi nilai ekstrim pada return saham Telekomunikasi Indonesia dan saham Gudang Garam. Nilai ekstrem tersebut dapat dilihat dari ekor Pareto bagian bawah maupun bagian atas pada masingmasing saham. Adanya nilai ekstrem ini dapat memengaruhi tingkat risiko yang mungkin ditanggung ke depannya.

\subsection{Mengestimasi Parameter Archimedean Copula}

Pada tahap ini dilakukan estimasi parameter pada keluarga Archimedean Copula. Adapun parameter dari keluarga Archimedean Copula adalah theta $(\theta)$. Pada tahap ini akan digunakan Kendall's tau yang dianggap cocok pada kasus bivariate serta pada data yang tidak berdistribusi normal. Sebelum mengertimasi parameter, hal yang dilakukan terlebih dahulu adalah mencari nilai $(\tau)$ dari saham PT. Telekomunikasi Indonesia Tbk (TLKM), dan PT. Gudang Garam Tbk (GGRM). Selanjutnya dari nilai $\tau$ yang telah diperoleh tersebut, digunakan untuk mengestimasi parameter keluarga Archimedean Copula. Dengan menggunakan software MATLAB 2013 diperoleh parameter keluarga Archimedean Copula yang dapat dilihat pada Tabel 4. 
Tabel 4. Parameter Keluarga Archimedean Copula

\begin{tabular}{|r|r|c|}
\hline Clayton & Gumbel & Frank \\
\hline$\theta=0,1659$ & $\theta=1,2345$ & $\theta=1,4262$ \\
\hline
\end{tabular}

\subsection{Simulasi Parameter Copula}

Pada tahap ini dilakukan simulasi data dengan membangkitkan sejumlah bilangan acak pada keluarga Archemedean Copula menggunakan parameter yang telah diperoleh. Simulasi dapat dilakukan sebanyak 700 kali (sejumlah yang diinginkan). Setelah memperoleh hasil simulasi data return, selanjutnya menentukan bobot (proporsi) dana yang ingin diinvestasikan untuk memperoleh return portofolio. Dari hasil yang telah diperoleh, selanjutnya menghitung nilai VaR sebesar tingkat kepercayaan yang telah ditentukan.

\subsection{Menghitung Nilai VaR Menggunakan Fungsi Archimedean Copula}

Value at Risk (VaR) adalah salah satu cara untuk mengukur risiko yang dapat dihitung besaran kerugian maksimum yang mungkin dialami dalam periode tertentu. Pada tahap ini menghitung nilai VaR dari return saham PT. Telekomunikasi Indonesia Tbk (TLKM), dan PT. Gudang Garam Tbk (GGRM) dengan menggunakan fungsi keluarga Archimedean Copula, dengan tingkat kepercayaan yang digunakan pada penelitian ini adalah $90 \%, 95 \%$, 99\%. Nilai VaR dari return saham PT. Telekomunikasi Indonesia Tbk (TLKM), dan PT. Gudang Garam Tbk (GGRM) dapat dilihat pada Tabel 5.

Tabel 5. Nilai VaR dari return saham TLKM dan GGRM

\begin{tabular}{|l|l|l|l|}
\hline \multicolumn{1}{|c|}{ VaR } & \multicolumn{3}{|c|}{ Tingkat Kepercayaan } \\
\hline & $90 \%$ & $95 \%$ & $99 \%$ \\
\hline Clayton & $0,9562 \%$ & $1,2930 \%$ & $2,0327 \%$ \\
\hline Gumbel & $1,0189 \%$ & $1,2522 \%$ & $1,9164 \%$ \\
\hline Frank & $0,9827 \%$ & $1,3152 \%$ & $1,8678 \%$ \\
\hline
\end{tabular}

Berdasarkan Tabel 5 intepretaasi yang bisa diberikan adalah untuk Clayton Copula pada tingkat kepercayaan 90\%, 95\%, dan 99\% memiliki nilai VaR berturut turut sebesar $0,9562 \%, 1,2930 \%$, dan $2,0327 \%$ yang berarti risiko kerugian yang mungkin dialami oleh investor suatu hari kedepan pada selang kepercayaan $90 \%, 95 \%$, dan $99 \%$ yaitu berturut turut sebesar $0,9562 \%, 1,2930 \%$, dan 2,0327\% dari aset yang diinvestasikan. Intepretasi yang sama berlaku untuk Gumbel Copula, dan Frank Copula.

Misalkan dengan memiliki modal sebesar Rp 1.000.000 maka kerugian yang mungkin dialami pada suatu hari ke depan oleh investor dengan tingkat kepercayaan $90 \%$ dengan menggunakan fungsi Clayton Copula yaitu sebesar Rp 9.562, sedangkan pada tingkat kepercayaan 95\% yaitu sebesar Rp 12. 930, dan pada tingkat kepercayaan $99 \%$ yaitu sebesar Rp 20.327. Untuk Gumbel Copula dengan tingkat kepercayaan 90\%, 95\%, dan 99\% kerugian yang mungkin dialami investor pada masa mendatang berturut turut adalah Rp 10.189, Rp 12.522, Rp 19.164. Untuk Frank Copula dengan tingkat kepercayaan 90\%, 95\%, dan 99\% kerugian yang mungkin dialami investor pada masa mendatang berturut turut adalah $\mathrm{Rp}$ 9.827, Rp 13.152, Rp 18.678. Terlihat bahwa semakin besar tingkat kepercayaan yang diambil semakin besar tingkat risiko yang diperoleh oleh investor.

\section{KESIMPULAN DAN SARAN}

Berdasarkan perhitungan dan pembahasan, diperoleh kesimpulan bahwa mengestimasi VaR menggunakan Archimedean copula dilakukan dengan (1) menghitung return saham PT. Telekomunikasi Indonesia Tbk (TLKM), dan PT. Gudang Garam Tbk (GGRM); (2) mencari nilai statistik deskriptif dari return yang diperoleh; (3) memeriksa adatidaknya sifat autokorelasi dan efek heteroskedastisitas pada data return masing masing saham. Jika data return memiliki sifat autokorelasi dan efek heteroskedastisitas, maka dapat memodelkan data return menggunakan model $\operatorname{GARCH}(1,1)$; (4) memeriksa keberadaan nilai ekstrem dengan 
menggunakan Pareto tail; (5) mengestimasi parameter keluarga Achimedean copula; (6) melakukan simulasi Archimedean copula sebanyak 700 kali selanjutnya mengestimasi nilai VaR saham portofolio.

Estimasi nilai VaR portofolio yang terdiri dari saham PT. Telkomunikasi Indonesia Tbk (TLKM), dan PT. Gudang Garam Tbk (GGRM) pada tingkat kepercayaan $90 \%$ dengan menggunakan fungsi Clayton copula sebesar $0,9562 \%$, sedangkan dengan menggunakan fungsi Gumbel colupa sebesar 1,0189\%, dan dengan menggunakan fungsi Frank copula sebesar $0,9827 \%$. Nilai VaR portofolio pada tingkat kepercayaan $95 \%$ dengan menggunakan fungsi Clayton copula sebesar 1,2930\%, sedangkan dengan menggunakan fungsi Gumbel colupa sebesar 1,2522\%, dan dengan menggunakan fungsi Frank copula sebesar $1,3152 \%$. Nilai $\mathrm{VaR}$ portofolio pada tingkat kepercayaan $99 \%$ dengan menggunakan fungsi Clayton Copula sebesar 2,0327\%, sedangkan dengan menggunakan fungsi Gumbel Colupa sebesar $1,9164 \%$, dan dengan menggunakan fungsi Frank Copula sebesar 1,8678\%. Terlihat bahwa semakin besar tingkat kepercayaan yang diambil semakin besar tingkat risiko yang diperoleh investor. Perhitungan estimasi nilai VaR portofolio menggunakan Clayton copula menghasilkan nilai VaR tertinggi.

Adapun saran yang diberikan yaitu penelitian ini dapat dikembangkan dengan menghitung nilai $\mathrm{VaR}$ dan $\mathrm{CVaR}$ menggunakan fungsi keluaga Archimedean copula yang lain seperti Joe copula dan Plackett copula.

\section{DAFTAR PUSTAKA}

Dharmawan, K. 2014. Estimasi Nilai VaR Portofolio Menggunakan Pendekatan tCopula. Jurnal Matematika, Sains, dan Teknologi, Vol. 15, No. 1, pp1-2.

2014. The Application of EVTGARCH-COPULA Model For The Estimation Of VaR Of a Portfolio. IndoMS Jurnal on Statistic, Vol 2, No. 1, pp 3-5.

Embrechts, P., McNeil, A., and Staumann, D. 2001. Correlation and Dependence in Risk
Management: Properties and Pitfalls, in Risk Management: Value at Risk and Beyond, ed. By M. Dempster and H. K. Moffatt, Cambridge University Press.

Franke, J., Hardle, W. and Hafner, C.M. 2008. Statistics of Financial Markets: An Introduction (second edition). Berlin: Springer.

Hidayati, H., Dharmawan, K., dan Sumarjaya, I.W. 2015. Estimasi Nilai Conditional Value At Risk Menggunakan Fungsi Gaussian Copula. E-Jurnal Matematika Vol.4(4), pp188194

Iriani Novella. 2013. Estimasi Value At Risck Pada Portovolio Saham Dengan Copula. Skripsi. Program Studi Matematika. Institut Teknologi Sepuluh Nopember. Surabaya.

Jogiyanto, Hartono. 2003. Teori Portofolio dan Analisis Investasi. Edisi 2. Yogyakarta: BPFE

Nelsen, R. B. 2006. An Introduction to Copula (secon edition). New York: Spinger.

Sunaryo, T. 2007. Manajemen Risiko Finansial. Jakarta: Selemba Empat.

Yamai, Y., and Yoshiba, T. 2005. Value-at-Risk Versus Expected Shortfall: A Practical Perspective. Journal of Banking \& Finance, Vol. 14, pp 1-5 